\title{
Impulsiveness and lack of inhibitory control in eating disorders
}

Citation for published version (APA):

Claes, L., Nederkoorn, C., Vandereycken, W., Guerrieri, R., \& Vertommen, H. (2006). Impulsiveness and lack of inhibitory control in eating disorders. Eating Behaviors, 7(3), 196-203.

https://doi.org/10.1016/j.eatbeh.2006.05.001

Document status and date:

Published: 01/01/2006

DOI:

10.1016/j.eatbeh.2006.05.001

Document Version:

Publisher's PDF, also known as Version of record

Document license:

Taverne

Please check the document version of this publication:

- A submitted manuscript is the version of the article upon submission and before peer-review. There can be important differences between the submitted version and the official published version of record.

People interested in the research are advised to contact the author for the final version of the publication, or visit the DOI to the publisher's website.

- The final author version and the galley proof are versions of the publication after peer review.

- The final published version features the final layout of the paper including the volume, issue and page numbers.

Link to publication

\footnotetext{
General rights rights.

- You may freely distribute the URL identifying the publication in the public portal. please follow below link for the End User Agreement:

www.umlib.nl/taverne-license

Take down policy

If you believe that this document breaches copyright please contact us at:

repository@maastrichtuniversity.nl

providing details and we will investigate your claim.
}

Copyright and moral rights for the publications made accessible in the public portal are retained by the authors and/or other copyright owners and it is a condition of accessing publications that users recognise and abide by the legal requirements associated with these

- Users may download and print one copy of any publication from the public portal for the purpose of private study or research.

- You may not further distribute the material or use it for any profit-making activity or commercial gain

If the publication is distributed under the terms of Article $25 \mathrm{fa}$ of the Dutch Copyright Act, indicated by the "Taverne" license above, 


\title{
Impulsiveness and lack of inhibitory control in eating disorders
}

\author{
Laurence Claes $^{\mathrm{a}, *}$, Chantal Nederkoorn ${ }^{\mathrm{b}}$, Walter Vandereycken ${ }^{\mathrm{a}}$, \\ Ramona Guerrieri ${ }^{\mathrm{b}}$, Hans Vertommen ${ }^{\mathrm{a}}$

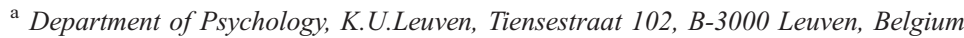 \\ ${ }^{\mathrm{b}}$ Department of Experimental Psychology, Maastricht University, P.O. Box 616, Maastricht 6200 MD, The Netherlands
}

Received 29 March 2006; received in revised form 30 April 2006; accepted 24 May 2006

\begin{abstract}
Eating disorders are considered to lie on a spectrum of disorders with varying degrees of obsessive-compulsive and impulsive traits. Restrictive anorexia nervosa patients (AN-R) are thought to belong to the obsessive pole of the spectrum, and purging-anorexia (AN-P) and bulimia nervosa (BN) patients to the impulsive pole. In this study we have compared impulsive traits in three groups of eating disordered patients (total $N=56$ ) and a control group of 83 female students. Information about impulsive traits and lack of inhibitory control was gathered by means of standardized rating scales (Eysenck's Impulsiveness Scale, Barrett's Impulsiveness Scale, and Carver and White's BIS/BAS scale) and a behavioral measure of impulsiveness (stop-go task). On the questionnaires AN$\mathrm{R}$ patients reported to be less impulsive than controls, AN-P and BN patients. In the stop-go task, we did not find significant differences between the different groups. Correlations between self-reported measures of impulsiveness and behavioral measures were not significant. In conclusion: Our results from the self-report measures are at odds with the behavioral measures certainly in the AN-R group. Perhaps the latter patients' distorted self-perception and/or self-description may explain this discrepancy.
\end{abstract}

(C) 2006 Elsevier Ltd. All rights reserved.

Keywords: Impulsiveness; Lack of inhibitory control; Stop-go task; Anorexia nervosa; Bulimia nervosa

\section{Introduction}

It has been suggested that anorexia nervosa of the restrictive type (AN-R), anorexia nervosa of the bingeing/purging type (AN-P) and bulimia nervosa (BN) all belong to a spectrum of disorders that present with varying degrees of obsessivecompulsive and impulsive traits (McElroy, Phillips, \& Keck, 1994). According to Hollander (1998), obsessive individuals may be hypervigilant and attempt to avoid harm and reduce anxiety or discomfort; in contrast, impulsive individuals are risk seekers who try to maximize pleasure, arousal or gratification and who may exhibit antisocial behaviors. Much has been written on obsessive-compulsive features in AN versus more impulsive traits in BN (for reviews see Dawe \& Loxton, 2004; Kaye, Bulik, Thornton, Barbarich, \& Masters, 2004). However, several authors have also recognized impulsive traits in AN subjects (particularly the bingeing-purging subtype) and obsessive-compulsive symptoms in BN subjects (e.g., Aragona \& Vella, 1998). Understanding the obsessive-compulsive and impulsive aspects in individuals with eating disorders may help guide treatment or allow for better prediction of outcome (Raymond et al., 1999).

\footnotetext{
* Corresponding author. Tel.: +32163261 33; fax: +32 16325916 .

E-mail address: Laurence.Claes@psy.kuleuven.be (L. Claes).
} 
Empirical studies of impulsiveness and lack of inhibitory control in general have used both self-report questionnaires and more objective behavioral measures (e.g., reaction time tasks), as indices of different aspects of the multi-dimensional impulsiveness construct (Malle \& Neubauer, 1991, see in Butler \& Montgomery, 2005). However, research on impulsiveness in eating disordered patients has mostly used self-report measures. Only a few authors have made use of behavioral measures to investigate impulsiveness and lack of inhibitory control in eating disordered patients (especially AN-R). Using a continuous performance task (CPT), Seed, Dixon, McCluskey, and Young (2000) found that women with AN responded to more nontargets (errors of commission, indicating impulsiveness) and missed more target stimuli (errors of omission, indicating inattention) than controls, without any differences in response latencies. Butler and Montgomery (2005) assessed impulsiveness in women with AN using the Impulsiveness Questionnaire of Eysenck ( $\mathrm{I}_{7}$; Eysenck \& Eysenck, 1978) and two behavioral measures (a continuous performance task and a risk-taking measure). The AN group had lower self-reported impulsiveness and venturesomeness scores than controls, but they also displayed impulsive behavior on the CPT (more errors of commission with faster reaction times). The authors concluded that the coexistence of self-reported self-control and behavioral impulsiveness in AN indicate that the relationship between impulsiveness and disordered eating in AN is more complex than previously recognized. Finally, Nederkoorn, Van Eijs, and Jansen (2004) used a stop-go task in 34 restrained eaters - who are expected to serve as an analogue of BN (Lowe et al., 1996) - and 29 control women: The former were significantly worse in inhibiting their motor responses than the unrestrained eaters. Food exposure during the task did not affect motor performance. The authors concluded that a fundamental lack of general response inhibition might play a role in the development of a specific eating disinhibition. This notion implies that the authors consider impulsivity to be a potential antecedent risk factor for AN. It would seem, however, that the starvation related implications of AN may have a significant effect on such behavioral measures of impulsivity. Fessler (2002) noted the possibility that "lack of response inhibition" might be an epiphenomena related to starvation. Increased impulsivity in association with dietary constriction is described in diverse literatures (see in Fessler, 2002). It appears that, via a reduction in serotonergic activity, fasting inherently increases levels of impulsivity in general, and impulsive aggressive in particular (Fessler, 2003).

The stop-go task used in the study by Nederkoorn et al. (2004) assesses the integrity of suppressing prepotent motor responses (inhibitory motor control). Inhibitory motor control is a hidden process. The main advantage of the stop task is that it can reveal this covert stop process by estimating the speed of stopping (SSRT). In the go task subjects are instructed to respond as quickly as possible to a particular stimulus (go stimulus). In some trials a second stimulus (stop stimulus) is presented closely in time to the go stimulus, with the indication to stop the response initiated by the go stimulus, assessing Stop-Signal Reaction Time (SSRT). According to Avila and Parcet (2001), the stop-go task is a valid and reliable measure of the inhibition process.

Lijffijt et al. (2004) investigated whether there is an association between trait impulsiveness in the normal population (as measures by questionnaires) and inhibitory motor control (as measured by the stop-go task). Low and high impulsive participants (as assessed by the $\mathrm{I}_{7}$ questionnaire, total of both groups $N=31$ ) performed the stop-go task. The low and high impulsive groups did not differ on the speed to stop the response (SSRT). Furthermore a short meta-analysis was performed on this study and three previous studies with a similar aim [Logan, Schachar, \& Tannock, 1997; Marsh, Dougherty, Mathias, Moeller, \& Hicks, 2002; Rodriquez-Fornells, Lorenzo-Seva, \& Andres-Pueyo, 2002]. However, the meta-analysis revealed that high-impulsive people are marginally slower in stopping than low-impulsives (effect-size $=-0.26 ; p=0.06$ ). Lijffijt et al. (2004) concluded that there is only minor evidence that impulsiveness in the common population is associated with inhibitory motor control. However, the stop-signal task has also been used in several studies with children with different psychiatric disorders (Avila \& Parcet, 2001). The results of a recent meta-analysis of eight studies in which response inhibition was assessed with the stop-signal task revealed that response inhibition deficits were more present in children with ADHD compared with controls, but also in those with Conduct Disorder (Oosterlaan, Logan, \& Sergeant, 2002). Another relevant result of the meta-analytic study was that anxious children did not show enhanced levels of response inhibition.

The goal of the present study was to find out whether the various types of eating disordered patients (AN-R, AN-P, BN) and normal controls differ from each other with respect to impulsiveness and lack of inhibitory control measured with subjective self-report measures of impulsiveness and a behavior measure of (lack of) inhibitory control (stop-go task). We hypothesized a gradual increase in self-reported (e.g. Claes, Vandereycken, \& Vertommen, 2005) impulsiveness from AN$\mathrm{R}$, over $\mathrm{AN}-\mathrm{P}$ to $\mathrm{BN}$, and $\mathrm{NC}$ taken a position between $\mathrm{AN}-\mathrm{R}$ and $\mathrm{AN}-\mathrm{P} / \mathrm{BN}$ patients. Formulating hypotheses concerning the results of the stop-go task in different ED groups is more difficult, due to a lack of literature concerning this topic. The available literature (e.g., Butler \& Montgomery, 2005; Nederkoorn et al., 2004; Seed et al., 2000) suggests that AN patients make more mistakes, react faster and have less inhibitory control than $\mathrm{NC}$, but no literature is available concerning the comparison of AN and BN patients on inhibitory control tasks. Based on literature on personality traits (Dawe \& Loxton, 
2004; Kaye et al., 2004), one would expect that BN patients have less inhibitory control than AN patients; but due to starvation AN patients can also display problems in inhibitory control. Finally, we are interested in the association between the self-reported measures of impulsivity and the lack of inhibitory control in the stop-go task.

\section{Method}

\subsection{Subjects}

We gathered data from 56 female eating disordered (ED) in/outpatients and 83 female healthy controls. By means of a clinical interview conducted by an experienced psychiatrist (third author) supplemented with the Eating Disorder Examination-Questionnaire (EDE-Q; Fairburn \& Beglin, 1994; Mond, Hay, Rodgers, Owen, \& Beumont, 2004) patients were diagnosed according to the DSM-IV criteria (American Psychiatric Association, 1994): 35.7\% $(N=20)$ as anorexia nervosa restrictive type (AN-R), 25\% $(N=14)$ as anorexia nervosa bingeing/purging type (AN-P), and 39.3\% $(N=22)$ as bulimia nervosa purging type (BN). The results of the EDE-Q showed significant differences between the four groups (Wilks' $\lambda=0.53, p<0.001$ ); the different types of ED patients scored significantly higher on the four EDE-Q subscales compared to NC, but did not significantly differ from each other with respect to Restraint, Eating Concern, Weight Concern and Shape Concern. The mean age of the AN-R, AN-P, BN and NCs (NC) was $23.0(\mathrm{SD}=6.6), 21.7(\mathrm{SD}=6.8), 22.7$ $(\mathrm{SD}=5.8)$ and $20.1(\mathrm{SD}=3.1)$ and were not significantly different from each other.

\subsection{Measures}

\subsubsection{Self-reported measures of impulsiveness}

2.2.1.1. Eysenck impulsiveness questionnaire $\left(I_{7}\right)$. The $I_{7}$ is a self-report inventory that consists of 54 items to be answered with a yes/no format. According to its authors (Eysenck \& Eysenck, 1978) the $\mathrm{I}_{7}$ is an adequate measure of three factors: Narrow Impulsiveness (N-Imp, 19 items, $\alpha=0.83 ; \alpha_{\text {our sample }}=0.81$ ), Venturesomeness (Vent, 16 items, $\alpha=0.84$; $\alpha_{\text {our sample }}=0.79$ ), and Empathy (Emp, 19 filler items, $\alpha=0.69 ; \alpha_{\text {our sample }}=0.60$ ). Impulsiveness - as measured by this instrument - is related to decision making without an awareness of risk, whereas venturesomeness describes decision making with due consideration of risks and consequences. Impulsiveness and venturesomeness are positively correlated $(r=0.38)$. The instrument is known to have good reliability and derived age norms (Eysenck, Pearson, Easting, \& Allsopp, 1985).

2.2.1.2. Barrett impulsiveness scale (BIS-11). The BIS-11 assesses different aspects of impulsiveness as a personality trait. The questionnaire consists of 30 statements to which participants respond by choosing one of the following responses: Rarely/never, occasionally, often, and almost always. An analysis of the factor structure of the BIS-11 (Patton, Stanford, \& Barratt, 1995) revealed six first-order and three second-order factors. The first-order factors were labeled as follows: Attention (focusing on the task at hand); Motor Impulsiveness (acting on the spur of the moment); Self-control (planning and thinking carefully); Cognitive Complexity (enjoy challenging mental tasks), Perseverance (a consistent life style) and Cognitive Instability (thought insertions and racing thoughts). The three second-order factors are: Attentional Impulsiveness $\left(\alpha_{\text {our sample }}=0.59\right)$, combining Non-Attention and Cognitive Instability; Motor Impulsiveness $\left(\alpha_{\text {our sample }}=0.64\right)$, combining Motor Impulsiveness and Non-Perseverance; and Non-planning Impulsiveness $\left(\alpha_{\text {our sample }}=0.71\right)$ combining Self-control and Cognitive Complexity. Alpha coefficients for the total BIS were within acceptable limits for use in applied studies across different groups (e.g., General psychiatric patients: $\alpha=0.83 ; \alpha_{\text {our sample }}=0.79$ ).

2.2.1.3. BIS-BAS measures. The BIS-BAS Scales (Carver \& White, 1994) are presented as a 20 item questionnaire. They have been designed specifically to measure the sensitivity of Gray's (1990) Behavioral Inhibition System (BIS) and Behavioral Activation System (BAS) at the personality level. In relation to behavior, this theory suggests that the BIS (trait anxiety) is sensitive to signals of punishment, frustrative non-reward and novelty, and when it is activated by such signals, it inhibits behavior that will lead to further negative or painful outcomes. In contrast, the BAS (trait impulsiveness) is believed to be sensitive to signals of reward and non-punishment, and when it is activated by such signals it causes or increases behavior toward more rewards or goals. Respondents are asked to endorse items on a 4-point 
Likert scale ranging form $1=$ strongly agree to $4=$ strongly disagree. The measure yields four scales: One for BIS and three BAS scales entitled Reward Responsiveness (items measuring anticipation and positive response towards reward), Drive (items tapping persistence in obtaining desired goals) and Fun Seeking (statements indicative of a willingness to seek out and spontaneously approach potentially rewarding experiences). Cronbach alpha coefficients were reported for the original sample. For the BIS scale $\alpha=0.74\left(\alpha_{\text {our sample }}=0.82\right)$; for Reward Responsiveness $\alpha=0.73\left(\alpha_{\text {our sample }}=0.68\right)$; for Drive $\alpha=0.76\left(\alpha_{\text {our sample }}=0.76\right)$; and for Fun Seeking $\alpha=0.66\left(\alpha_{\text {our sample }}=0.56\right)$ (Heubeck, Wilkinson, \& Cologon, 1998).

\subsubsection{The stop-go task}

The stop-go task was copied from Logan et al. (1997). It involves two concurrent tasks, a go task, which is a choice reaction time task, and a stop task, occurring on $25 \%$ of the go-trial, and involving a stop-signal that tells subjects to inhibit their responses to the go task. During the go task, the letters $\mathrm{O}$ or X were presented for $1000 \mathrm{~ms}$ on the center of a PC computer screen, preceded by a $500 \mathrm{~ms}$ fixation point. The subjects had to press a right button on a board with their right hand when an $\mathrm{X}$ was on the screen and a left button with their left hand when an $\mathrm{O}$ was on the screen. Between trials, the screen was blank for $1000 \mathrm{~ms}$. The subjects were asked to press the buttons as fast as possible. In the go task subjects are instructed to respond as quickly as possible to a particular stimulus (go stimulus), generating measures such as the \% correct answers on the Go Task (\% of go trials on which one pressed left when $\mathrm{O}$ appeared and right when X appeared on the screen), the Mean Reaction Time $\left(M_{\mathrm{RT}}\right)$, and Within-Subject Standard Deviation of the Reaction Time $\left(\mathrm{SD}_{\mathrm{RT}}\right)$, that possibly reflect lapses of attention (Castellanos \& Tannock, 2002). The stop-signal was a $100 \mathrm{~ms}, 1000 \mathrm{~Hz}$ tone, produced by the computer. Initially, the stop-signal delay was set at $250 \mathrm{~ms}$ after the presentation of the go signal (the $\mathrm{O}$ or the $\mathrm{X}$ ) and then adjusted dynamically depending on the responses of the subject (tracking procedure designed to allow subject to inhibit on $50 \%$ of the stop-signal trials). When the subject failed to inhibit the response, the delay was decreased by $50 \mathrm{~ms}$, thereby making it easier to inhibit the next stop-signal trial. When the subject succeeded in inhibiting the response, the delay was increased by $50 \mathrm{~ms}$, thereby making it more difficult to inhibit the next stop-signal trial. The variables measured in this task are the $\%$ No Inhibition (referring to the \% of stop trials on which one did not inhibit one's response when the stop-signal was generated), the Reaction Time (RT) and the Stop Delay. The Stop-Signal Reaction Time (SSRT) is calculated by subtracting the Stop Delay from the Reaction Time. Higher SSRTs indicate poorer response inhibition. The task consists of four blocks, each containing 128 trials. There were an equal number of Xs and Os in a block and stopsignals were presented on $25 \%$ of the trials, balanced over X and $\mathrm{O}$ trials. The order of trials was randomized. Between blocks, the subject was allowed to take a break of a few minutes (Nederkoorn et al., 2004).

\subsection{Procedure}

The participants were tested individually. They signed an informed consent prior to participation. Approval was given by the ethical board of the university. The participants started with the stop-signal task. They were explicitly told that their first priority was to respond as fast as possible to the choice reaction task and not to wait for the tone. When the computer task was completed, the patient filled out the questionnaires.

\subsection{Analyses}

The data of the stop-go task were analyzed with 4 (group) $\times 4$ (blocks) analyses of variance (ANOVA) for repeated measures. Data of the questionnaires were analyzed with multivariate analyses of variance (MANOVAs), followed by univariate analyses of variance (ANOVAs) and Scheffe's post-hoc tests to find the significant differences between the four groups (SPSS, version 11). To calculate the relationship between the interval-scaled variables, we used the zero-order correlation coefficient.

\section{Results}

\subsection{Associations between self-reported measures of impulsiveness and the stop-go task measures}

Within the self-reported measures of impulsiveness, Motor Impulsiveness ( $\left.\mathrm{I}_{7}, \mathrm{BIS}\right)$, Venturesomeness $\left(\mathrm{I}_{7}\right)$, NonPlanning Impulsiveness (BIS), Drive and Fun Seeking (BIS/BAS) are positively correlated with each other $(r$ ranging 
Table 1

Means (standard deviations) of self-reported measures of impulsiveness and stop-go task measures in the different types of ED and controls

\begin{tabular}{|c|c|c|c|c|c|c|c|c|c|}
\hline \multicolumn{2}{|c|}{ (A) AN-R $(N=20)$} & \multicolumn{2}{|c|}{ (B) AN-P $(N=14)$} & \multicolumn{2}{|c|}{ (C) $\mathrm{BN}(N=22)$} & \multicolumn{2}{|c|}{$\begin{array}{l}\text { (D) Controls } \\
(N=83) \\
\end{array}$} & \multirow[t]{2}{*}{$\mathrm{F}$} & \multirow[t]{2}{*}{$\begin{array}{l}\text { Post-hoc } \\
\text { tests }\end{array}$} \\
\hline M & (SD) & M & (SD) & M & (SD) & M & (SD) & & \\
\hline
\end{tabular}

\begin{tabular}{|c|c|c|c|c|c|c|c|c|c|c|}
\hline \multicolumn{11}{|c|}{ Self-reported measures of impulsiveness } \\
\hline \multicolumn{11}{|c|}{ Eysenk Impulsiveness Questionnaire } \\
\hline Impulsiveness & 4.05 & $(2.2)$ & 8.00 & $(3.8)$ & 7.77 & $(4.5)$ & 7.00 & $(4.2)$ & $3.96 * *$ & $\mathrm{~B}, \mathrm{C}, \mathrm{D}>\mathrm{A}$ \\
\hline Venturesomeness & 6.00 & (3.9) & 9.46 & (3.7) & 9.22 & $(4.3)$ & 8.88 & (3.3) & $4.00 * * *$ & $\mathrm{~B}, \mathrm{C}, \mathrm{D}>\mathrm{A}$ \\
\hline Empathy & 15.8 & $(2.3)$ & 15.6 & $(2.0)$ & 15.3 & (3.3) & 15.4 & $(2.1)$ & 0.16 & n.s. \\
\hline \multicolumn{11}{|c|}{ Barrett Impulsiveness Scale } \\
\hline Attentional imp. & 17.5 & $(4.4)$ & 19.3 & $(3.7)$ & 18.8 & $(3.7)$ & 16.8 & $(3.2)$ & $2.96^{*}$ & $\mathrm{~B}, \mathrm{C}>\mathrm{D}$ \\
\hline Motor imp. & 17.5 & (3.3) & 21.4 & $(2.9)$ & 21.9 & $(4.1)$ & 22.6 & (4.3) & $8.28 * * *$ & $\mathrm{~B}, \mathrm{C}, \mathrm{D}>\mathrm{A}$ \\
\hline $\begin{array}{l}\text { Non-planning imp. } \\
\text { BIS/BAS Scale }\end{array}$ & 23.9 & $(5.0)$ & 27.4 & $(5.6)$ & 27.7 & $(5.2)$ & 27.2 & (4.3) & $2.89 *$ & $\mathrm{C}, \mathrm{D}>\mathrm{A}$ \\
\hline BIS & 25.3 & (3.2) & 21.7 & $(6.8)$ & 24.3 & $(4.0)$ & 22.5 & (3.1) & $4.03 * *$ & $A>B, D$ \\
\hline BAS-Total & 36.0 & $(4.7)$ & 35.7 & $(6.6)$ & 37.8 & $(5.9)$ & 39.4 & $(4.5)$ & $3.69 *$ & $\mathrm{D}>\mathrm{A}$ \\
\hline Reward respons. & 16.2 & $(3.2)$ & 15.4 & $(3.5)$ & 16.3 & $(2.7)$ & 17.1 & (1.8) & 2.48 & n.s. \\
\hline Drive & 10.2 & (2.8) & 9.8 & $(2.2)$ & 10.30 & $(2.6)$ & 10.2 & (2.2) & 0.11 & n.s. \\
\hline Fun seeking & 9.5 & $(2.2)$ & 10.5 & $(2.5)$ & 11.1 & $(2.0)$ & 12.0 & (1.9) & $8.28 * * *$ & $\mathrm{C}, \mathrm{D}>\mathrm{A}$ \\
\hline \multicolumn{11}{|c|}{$\begin{array}{l}\text { Stop-go task measures (results aggregated over blocks 1-4) } \\
\text { Go task }\end{array}$} \\
\hline Mean RT (in ms) & 529.5 & 96.7 & 521.0 & 83.4 & 475.1 & 103.7 & 538.9 & 132.3 & 1.65 & n.s. \\
\hline SD of RT (in ms) & 105.2 & 17.5 & 107.3 & 20.0 & 96.7 & 22.4 & 107.5 & 25.7 & 1.24 & n.s. \\
\hline$\%$ correct & 93.6 & 2.2 & 93.8 & 2.2 & 94.4 & 1.4 & 92.1 & 8.8 & 0.86 & n.s. \\
\hline $\begin{array}{l}\text { Stop-signal delay } \\
\text { (in } \mathrm{ms} \text { ) }\end{array}$ & 351.7 & 119.0 & 350.0 & 114.0 & 309.7 & 122.4 & 378.0 & 164.0 & 1.29 & n.s. \\
\hline Stop task & & & & & & & & & & \\
\hline$\%$ no inhibition & 0.49 & 0.02 & 0.50 & 0.03 & 0.49 & 0.01 & 0.49 & 0.05 & 0.17 & n.s. \\
\hline SSRT (in ms) & 177.8 & 53.2 & 171.0 & 56.9 & 165.4 & 34.4 & 160.8 & 44.4 & 0.81 & n.s. \\
\hline
\end{tabular}

$p<0.05, * * p<0.01, * * * p<0.001$.

from 0.23 to $0.68 ; p<0.01$ ); and negatively with Empathy $\left(\mathrm{I}_{7}\right)$ and Behavioral Inhibition (BIS/BAS), which are positively $(r=0.46, p<0.001)$ associated with each other.

Within the stop-go task, the Mean Reaction Time is positively correlated to the Stop-Signal Delay $(r=0.96, p<0.001)$ and negatively to the Percentage of No Inhibition in the Stop Task $(r=-0.62, p<0.001)$ and the SSRT $(r=-0.49$, $p<0.001)$. The faster the person reacts to the go stimulus, the shorter the stop-signal delay needs to be set, the more disinhibition errors occur and the longer the SSRT (indicating a lack of inhibitory control). Furthermore, the Stop-Signal Delay is consistently negatively correlated with Percentage No Inhibition $(r=-0.71, p<0.001)$ and SSRT $(r=-0.71$, $p<0.001$ ), indicating that persons who need a short Stop-Signal Delay make more disinhibition errors and have a longer SSRT (indicating a lack of inhibitory control). Finally, persons with a longer SSRT make more disinhibition errors, as can be seen in the positive correlation between SSRT and Percentage No Inhibition $(r=0.67, p<0.001)$.

Finally, we calculated the correlations between the self-reported measures and behavioral measures of impulsiveness/ lack of inhibitory control. Overall, we did not find significant correlations between the self-reported measures of impulsiveness and the behavioral measures of lack of inhibitory control.

\subsection{Differences in self-reported measures of impulsiveness and stop-go task measures in ED and NC}

\subsubsection{Self-reported measures of impulsiveness}

To find out whether the ED patients and NC significantly differ from each other with respect to the self-reported measure of impulsiveness, we performed three MANOVA's with the types of ED/NC as independent variable and the subscales of the BIS (Wilks' $\lambda=0.71, p<0.001$ ), the $\mathrm{I}_{7}$ (Wilks' $\lambda=0.87, p<0.05$ ), and the BIS/BAS (Wilks' $\lambda=0.70$, $p<0.001$ ) as dependent variables (see Table 1 ). The different types of ED patients and the NC significantly differ from each other with respect to the self-reported measures of impulsiveness. With respect to Motor Impulsiveness $\left(\mathrm{I}_{7}\right.$ Impulsiveness, BIS-Motor Impulsiveness, BIS-Non-Planning Impulsiveness), referring to acting on the spur of the moment and a lack of 
self-control, AN-P, BN and NC are significantly more impulsive than AN-R patients. Comparable results are found for Venturesomeness ( $\mathrm{I}_{7}$ Venturesomeness, BIS/BAS-Fun Seeking) referring to thrill and adventure-seeking behavior. Again, AN-P, BN, and NC are more fun-seeking than AN-R patients. In the same way, AN-R patients are more behaviorally inhibited (BIS/BAS-Behavioral inhibition) than BN-P and NC. Finally, the different types of ED patients (except for AN$\mathrm{R})$ have more attention problems (BIS-Attentional Impulsiveness) than NC.

\subsubsection{Stop-go task measures}

The data of the stop-go task were analyzed with 4 (groups) $\times 4$ (blocks) ANOVA for repeated measures. We did not find significant group effects (AN-R, AN-P, BN and NC) for all the dependent variables (see Table 1). The decrease in Mean Reaction Time (gradually from NC over AN-R, AN-P, BN) and the decrease in Stop-Signal Delay (referring to a decrease in inhibitory control, gradually from $\mathrm{NC}$ over AN-R, AN-P and BN) were nearly significant (certainly the differences between the AN-R and the BN group). However, we did not find a gradual increase in SSRT (referring to lack of inhibitory control) from NC and AN-R over AN-P to BN. Furthermore, we did not find significant differences between the different groups with respect to Percentage Correct Answers on the go task and Percentage No-Inhibited Responses on the stop task. The stop-go task was after all designed to let participants be able to inhibit $50 \%$ of the stop trails (tracking procedure). The mean percentages of trials that were inhibited were $50 \%, 49 \%, 51 \%$, and $51 \%$ respectively for the AN-R, AN-P, BN and $\mathrm{NC}$, indicating that the task was well executed by the participants. Furthermore, we found significant block effects for $M_{\mathrm{RT}}$, $\mathrm{SD}_{\mathrm{RT}}$, Stop-Signal Delay, \% No Inhibition and SSRT. This effect was due to the improvement of the four groups after the first block. Aside from the learning/habituating effect, no differences between blocks were found as analyses excluding the first block found no effect of blocks.

\section{Discussion}

Confirming the findings by other researchers (e.g., Sohlberg, 1991), we found self-reported lack of impulsiveness (or increased self-control) to be associated with AN-R. On the whole, the bingeing-purging anorectics seem to have more in common with BN patients than with restricting anorectics, a finding which is consistent with the results of other studies (e.g. De Silva \& Eysenck, 1987; Toner, Garfinkel, \& Garner, 1987). Even in comparison with NC, our AN-R patients reported less $\mathrm{I}_{7}$ Impulsiveness and Venturesomeness scores, results that are confirmed by other researchers (e.g., Butler \& Montgomery, 2005). Also the correlational patterns of the self-reported impulsiveness measures were in line with the results of other researchers: (a) $\mathrm{I}_{7}$ Impulsiveness and Venturesomeness were positively correlated whereas the correlation between these two scales with empathy was notably lower and negative in the female group (e.g., Lijffijt, Caci, \& Kenemans, 2005); (b) Barrett Impulsiveness Scales were all positively interrelated, and $\mathrm{I}_{7}$ Impulsiveness was most strongly related to the Barrett Motor Impulsiveness Scale (Luengo, Carrillo de la Pena, \& Otero, 1991); (c) The BIS/BAS behavioral inhibition subscale was positively correlated with $\mathrm{I}_{7}$ Empathy, and for the most part negatively correlated with the other impulsiveness measures.

Unlike the self-reported measures of impulsiveness, the stop-go task (behavioral measure of lack of inhibitory control) failed to find differences between the different ED groups and NC. We found a — non significant — decrease in the Mean Reaction Time from NC over AN-R, AN-P and BN, and a decrease in the Stop-Signal Delay (referring to an increase in disinhibition) from NC over AN-R, AN-P and BN. We did not find an increase in SSRT (referring to a lack of inhibitory control) from NC and AN-R, over AN-P to BN. This apparent conflict may — according to Fessler (2002, 2003) - derive from a lack of inhibitory control in AN patients due to starvation or according to Butler and Montgomery (2005) - derive from the nature of self-reported assessments, which measure how participants view themselves, whereas objective measures reflect behavior. Future research, that makes use of larger samples of different ED subtypes and various measures of behavioral impulsiveness, will find out whether our results can be confirmed or rejected. However, the correlations between the different measures of the behavioral task were comparable with the results of other researchers (e.g., Avila \& Parcet, 2001). The Mean Reaction Time was positively correlated to the Stop-Signal Delay and negatively to the Percentage of No Inhibition. Furthermore, the Stop-Signal Delay was negatively correlated to the Percentage of No Inhibition and SSRT.

Finally, the absence of significant correlations between the self-reported and behavioral measures of impulsiveness in our results, confirm the different nature of both types of measures. These findings are in line with the results of other researchers. Lijffijt et al. (2004) concluded that there is only minor evidence that self-reported impulsiveness is associated with inhibitory motor (behavioral) control. 
According to Butler and Montgomery (2005) it seems appropriate to conclude that results from the self-report measure are at odds with the behavioral measures and probably reflect either a lack of self-awareness in AN-R, or a desire for selfcontrol that is not evident in such tests. Butler and Montgomery (2005) also notice that research into the time-course of AN has indicated that although a small proportion of patients successfully manage to restrict their eating over protracted periods, for many the hypercontrol eventually breaks down (Keel et al., 2005) and they can move to the bingeing-purging type of $\mathrm{AN}$ and then to BN. This suggests that levels of self-control and impulsiveness can change over time and this may have important implications for theory (is impulsiveness more a trait than a state in ED patients?) and for treatment. Butler and Montgomery (2005) concluded that monitoring of changes to the impulsiveness profile over time might provide a basis for clinical interventions aimed at (a) addressing self-control/impulsiveness issues without necessarily having to directly confront eating behavior, thus possibly avoiding treatment resistance, and (b) interrupting the transition from AN to BN and the associated worsening of the prognosis (Fichter, Quadflieg, \& Rief, 1994).

\section{References}

American Psychiatric Association. (1994). Diagnostic and statistical manual of mental disorders (fourth edition). Washington, DC: Author.

Aragona, M. and Vella, G. (1998). Psychopathological considerations on the relationship between bulimia and obsessive-compulsive disorder. Psychopathology, 31, 197-205.

Avila, C. and Parcet, M. A. (2001). Personality and inhibitory deficits in the stop-signal task: The mediating role of Gray's anxiety and impulsivity. Personality and Individual Differences, 31, 975-986.

Butler, G. K. L. and Montgomery, A. M. J. (2005). Subjective self-control and behavioral impulsivity coexist in anorexia nervosa. Eating Behaviors, 6, 221-227.

Carver, C. S. and White, T. L. (1994). Behavioral inhibition, behavioral activation, and affective responses to impending reward and punishment: The BIS/BAS Scales. Journal of Personality and Social Psychology, 67, 319-333.

Castellanos, F. X. and Tannock, R. (2002). Neuroscience of attention-deficit/hyperactivity disorder: the search for endophenotypes. Nature Reviews. Neuroscience, 3, 617-628.

Claes, L., Vandereycken, W., \& Vertommen, H. (2005). Impulsivity-related traits in eating disorder patients. Personality and Individual Differences, 39, 739-749.

Dawe, S. and Loxton, N. J. (2004). The role of impulsivity in the development of substance use and eating disorders. Neuroscience and Biobehavioral Reviews, 28, 343-351.

De Silva, P. and Eysenck, S. (1987). Personality and addictiveness in anorexic and bulimic patients. Personality and Individual Differences, 8, $749-751$.

Eysenck, S. B. and Eysenck, H. J. (1978). Impulsiveness and venturesomeness: Their position in a dimensional system of personality description. Psychological Reports, 43, 1247-1255.

Eysenck, S. B., Pearson, P. R., Easting, G., \& Allsopp, J. F. (1985). Age norms for impulsiveness, venturesomeness and empathy in adults Personality and Individual Differences, 6, 613-619.

Fairburn, C. G. and Beglin, S. J. (1994). Assessment of eating disorders: Interview or self-report questionnaire? International Journal of Eating Disorders, 16, 363-370.

Fessler, D. M. T. (2002). Pseudoparadoxical impulsivity in restrictive anorexia nervosa: A consequence of the logic of scarcity. International Journal of Eating Disorders, 31, 376-388.

Fessler, D. M. T. (2003). The implications of starvation induced psychological changes for the ethical treatment of hunger strikers. Journal of Medical Ethics, 29, 243-247.

Fichter, M. M., Quadflieg, N., \& Rief, W. (1994). Course of multi-impulsive bulimia. Psychological Medicine, 24, 591-604.

Gray, J. A. (1990). Brain systems that mediate both emotion and cognition. Cognition and Emotion, 4, 269-288.

Heubeck, B. G., Wilkinson, R. B., \& Cologon, J. (1998). A second look at Carver and White's (1994) BIS/BAS scales. Personality and Individual Differences, 25, 785-800.

Hollander, E. (1998). Treatment of obsessive-compulsive spectrum disorders with SSRI's. British Journal of Psychiatry, 173, 7-12.

Kaye, W., Bulik, C., Thornton, L., Barbarich, N., \& Masters, K. (2004). Comorbidity of anxiety disorders with anorexia and bulimia nervosa. American Journal of Psychiatry, 161, 2215-2221.

Keel, P., Plotnicov, K. H., Pollice, C., Lilenfeld, L. R., Berrettini, W. H., Bulik, C. M., et al. (2005). Symptom fluctuation in eating disorders: Correlates of diagnostic crossover. American Journal of Psychiatry, 162, 732-740.

Lijffijt, M., Bekker, E. M., Quick, E. H., Bakker, J., Kenemans, J. L., \& Verbaten, M. N. (2004). Differences between low and high trait impulsivity are not associated with differences in inhibitory motor control. Journal of Attention Disorders, 8, 25-32.

Lijffijt, M., Caci, H., \& Kenemans, J. L. (2005). Validation of the Dutch translation of the I-sub-7 questionnaire. Personality and Individual Differences, 38, 1123-1133.

Logan, G. D., Schachar, R. J., \& Tannock, R. (1997). Impulsivity and inhibitory control. Psychological Science, 8, 60-64.

Lowe, M. R., Gleaves, D. H., DiSimone-Weiss, R. T., Furgueson, C., Gayda, C. A., Kolsky, P. A., et al. (1996). Restraint, dieting, and the continuum model of bulimia nervosa. Journal of Abnormal Psychology, 105, 508-517.

Luengo, M. A., Carrillo de la Pena, M. T., \& Otero, J. M. (1991). The components of impulsiveness: A comparison of the I.7 Impulsiveness Questionnaire and the Barratt Impulsiveness Scale. Personality and Individual Differences, 12, 657-667. 
Malle, B. F. and Neubauer, A. C. (1991). Impulsivity, reflection, and questionnaire response latencies: No evidence for a broad impulsivity trait. Personality and Individual Differences, 12, 865-871.

Marsh, D. M., Dougherty, D. M., Mathias, C. W., Moeller, F. G., \& Hicks, L. R. (2002). Comparisons of women with high and low trait impulsivity using behavioral models of response disinhibition and reward choice. Personality and Individual Differences, 33, $1291-1310$.

McElroy, S. L., Phillips, K. A., \& Keck, P. E. (1994). Obsessive compulsive spectrum disorders. Journal of Clinical Psychiatry, 55, 33-51.

Mond, J. M., Hay, P. J., Rodgers, B., Owen, C., \& Beumont, P. J. V. (2004). Validity of the Eating Disorder Examination Questionnaire (EDE-Q) in screening for eating disorders in community samples. Behaviour Research and Therapy, 42, 551-567.

Oosterlaan, J., Logan, G., \& Sergeant, J. A. (2002). Response inhibition in AD/HD, CD, comorbid AD/HD CD, anxious, and control children: A meta-analysis of studies with the stop task. Journal of Child Psychology and Psychiatry and Allied Disciplines, 39, 411-425.

Nederkoorn, C., Van Eijs, Y., \& Jansen, A. (2004). Restrained eaters act on impulse. Personality and Individual Differences, $37,1651-1658$.

Patton, J. H., Stanford, M. S., \& Barratt, E. S. (1995). Factor structure of the Barratt Impulsiveness Scale. Journal of Clinical Psychology, 51, 768-774.

Raymond, N. C., Neumeyer, B., Thuras, P., Weller, C. L., Eckert, E. D., Crow, S. J., et al. (1999). Compulsive and impulsive traits in individuals with obese binge eating disorder and bulimia nervosa. Eating Disorders: The Journal of Treatment and Prevention, 7, $299-317$.

Rodriguez-Fornells, A., Lorenzo-Seva, U., \& Andres-Pueyo, A. (2002). Are high-impulsive and high risk-taking people more motor disinhibited in the presence of incentive? Personality and Individual Differences, 32, 661-683.

Seed, J. A., Dixon, R. A., McCluskey, S. E., \& Young, A. H. (2000). Basal activity of the hypothalamic-pituitary-adrenal axis and cognitive function in anorexia nervosa. European Archives of Psychiatry and Clinical Neuroscience, 250, 11-15.

Sohlberg, S. (1991). Impulse regulation in anorexia nervosa and bulimia nervosa: Some formulations. Behavioral Neurology, 4, $189-202$.

Toner, B. B., Garfinkel, P. E., \& Garner, D. M. (1987). Cognitive style of patients with bulimic and diet-restricting anorexia nervosa. American Journal of Psychiatry, 144, 510-512. 